\title{
Experiências exitosas no ensino de português para estrangeiros no ISF-UFAL
}

\section{Successful experiences in teaching Portuguese to foreign at ISF- UFAL}

\section{Experiencias exitosas en la enseñanza de Portugués a extranjeros en ISF-UFAL}

\author{
Eliane Vitorino de Moura Oliveira ${ }^{1}$ (ii) https://orcid.org/0000-0002-0698-3795 \\ Raul de Carvallho Rocha ${ }^{2}$ (iD) https://orcid.org/0000-0001-8118-3520 \\ Ringo Star Holanda Cavalcante 3 (D) https://orcid.org/0000-0002-9835-9622 \\ Waldenia Maria da Silva ${ }^{4}$ (iD) https://orcid.org/0000-0001-5906-3709
}

\begin{abstract}
RESUMO: Apresenta-se, neste artigo, um relato de experiência docente realizada em dois cursos de ensino de Português para Estrangeiros, no âmbito do Idioma sem Fronteiras (ISF) da Faculdade de Letras-UFAL, em que língua e cultura, ou língua-cultura, nas palavras de Mendes (2015), são trabalhadas associadamente, tanto no ensino de gêneros acadêmicos, quanto nas abordagens apresentadas em filmes com temáticas Nordestinas. Objetivamos, com o trabalho, refletir sobre a relevância do olhar altruísta sobre a língua-cultura do outro, e levar o outro a nos enxergar sob a mesma lente. A fundamentação se dá nas teorias da Linguística Aplicada, em sua visão sobre o ensino-aprendizagem de línguas, em especial à relacionada ao Português como Língua Estrangeira (PLE) e a partir de uma pesquisa qualitativa, que analisa o ambiente natural da sala de aula, utilizando a observação como técnica. Com as discussões, conclui-se que a prática pedagógica utilizada, nomeadamente a abordagem intercultural em aulas dialogadas e reflexivas, foi relevante para a concreta aprendizagem dos alunos de outras línguas.
\end{abstract}

PALAVRAS-CHAVE: Interculturalidade. Português Língua Estrangeira. ISF.

ABSTRACT: This paper presents a teaching experience report developed in two courses of Portuguese for Foreigners, which is part of Faculty of Language (Fale) of University of Alagoas' (UFAL) program: the Language without Borders (ISF). Such program deals with language and

\footnotetext{
${ }^{1}$ Doutora em Estudos da Linguagem. Docente no Curso de Letras, Universidade Federal de Alagoas/Campus Arapiraca. E-mail: eliane.oliveira@arapiraca.ufal.br

2 Graduando em Letras-Português. Universidade Federal de Alagoas. E-mail: raul.caarvalho@gmail.com

${ }^{3}$ Mestrando em Literatura no PPGLL/FALE/UFAL. E-mail: star-ringo@hotmail.com

${ }^{4}$ Mestranda em Linguística no PPGLL/FALE/UFAL. E-mail: waldenia.wms@hotmail.com
} 
culture, or language-culture, in the words of Mendes (2015), in a way that they are both worked together; it means it is academically taught, but also there is an approach using films with Northeastern themes. Based on the theories of Applied Linguistics, in its view of teaching and learning languages, and making use of a qualitative research, which analyses the natural environment of the classroom using observation as a technique, it is concluded that the pedagogical practice used - the intercultural approach in dialogue and reflective classes - was relevant to the students' concrete learning.

KEYWORDS: Interculturality. Portuguese Foreign language. ISF.

RESUMEN: Este artículo presenta un informe de experiencia docente desarrollado en dos cursos de portugués para extranjeros, que forma parte del programa de la Facultad de Letras (Fale) de la Universidad Federal de Alagoas (UFAL): Idioma sin Fronteras (ISF). Dicho programa se ocupa de la lengua y la cultura, o lengua-cultura, en palabras de Mendes (2015), de forma que ambas se trabajen juntas; significa que se enseña académicamente, pero también hay un enfoque que utiliza películas con temática nororiental. Partiendo de las teorías de la Lingüística Aplicada, en su visión de la enseñanza y el aprendizaje de idiomas, y haciendo uso de una investigación cualitativa, que analiza el entorno natural del aula utilizando la observación como técnica, se concluye que la práctica pedagógica utilizada - la interculturalidad enfoque en clases de diálogo y reflexión - fue relevante para el aprendizaje concreto de los estudiantes.

PALABRAS CLAVE: Interculturalidad. Portugués Lengua Extranjera. ISF.

\section{Introdução}

Ensinar Português como Língua Estrangeira (PLE) é uma tarefa que exige bastante dos docentes que se inserem por essas veredas, devido a suas especificidades: é preciso ter noções linguísticas da língua em foco tanto como Língua Materna (LM) e conhecimentos didático-pedagógicos para o ensino como Língua Não Materna (LNM).

De acordo com Almeida Filho (2012), o ensino de PLE iniciou-se na década de 60, mas, ainda hoje ele não tem a sistematização necessária. Na Universidade Federal de Alagoas, essa vertente do ensino acontece por meio do programa Idioma sem Fronteiras, sem que haja, no entanto, uma formação específica para este trabalho. Ainda assim, aceitamos o desafio de ofertar dois cursos de PLE para os alunos falantes de outras línguas que estudam em cursos de Graduação e Pós-Graduação na Universidade.

Neste artigo, relatamos um pouco desta experiência, com o objetivo de apresentar a abordagem intercultural, que vê língua e cultura como indissociáveis, como a mais eficiente para um aprendizado efetivo.

Nas próximas seções, apresentamos nosso embasamento teórico, que segue as teorias da Linguística Aplicada quando se volta ao ensino-aprendizagem de línguas, e em teóricos como Batista e Alarcon (2012), Almeida Filho (2012), Mendes (2012, 2015), entre 
outros, para, na sequência, relatar efetivamente as aulas, apresentando também nossas reflexões, concluindo com nossas considerações finais.

\section{O ensino de Português como LE}

A visão que um professor possui de língua/linguagem auxilia na construção de sua didática e interfere diretamente na forma como ele se posiciona diante do processo de ensino-aprendizagem. Desse modo, ao considerar que "uma língua natural equivale à produção e condição de vida real em sociedade" (BATISTA; ALARCON, 2012, p. 01), que ela é (re)construída nas e pelas interações sociais que os/as falantes dessa língua constroem dentro de uma coletividade, fato que pressupõe sociabilidade para que ela emerja, mostramos que a língua é constituída e se desenvolve em relações sociais, histórica e culturalmente situadas (BATISTA; ALARCóN, 2012). Assim, as significações formadas na e pela língua só podem ser compreendidas se houver um compartilhamento de conhecimentos comuns aos falantes dessa língua. Segundo Batista e Alarcón (2012, p. 01),

a língua revela um todo múltiplo numa pluralidade de mundos ou espaços. Assim, ensinar línguas é ensinar o social, o humano, o político, o histórico, o geográfico e o econômico de um povo, compreendendo sua cultura, sua identidade, sua diversidade, contradições e desigualdade de gênero, classes, religiões e emblemas pelos tantos que utilizam a mesma língua

Dessa forma, ao ensinar uma língua, estaríamos ensinando uma língua-cultura, em que a cultura não antecede ou sucede a língua, nem estão uma contida uma na outra: elas ocupam o mesmo lugar (MENDES, 2015). Diante desta perspectiva, pode-se afirmar que a Língua Portuguesa não representa apenas um sistema complexo de estruturas formais que envolvem aspectos morfológicos, fonológicos, fonéticos, sintáticos e semânticos, mas, também, constitui um fenômeno social de construção da realidade, dos nossos modos de pensar e formas de agir, influenciado por códigos socioculturais historicamente situados que não devem ser desconsiderados (MENDES, 2015).

Segundo Mendes (2015), a Língua Portuguesa, com sua diversidade linguística, apresenta várias normas de acordo com as variedades dos países luso-falantes. Assim, ao abordarmos o Português, temos que levar em consideração dois pontos:(i) que essa língua estabelece um contínuo de regras que a classifica como Portuguesa; e (ii) que ela 
apresenta diferenças ideológicas, sócio-históricas e identitárias, que Ihe atribuem especificidades.

Pode-se dizer que os países nos quais o Português é língua oficial têm uma "língua representada por diferentes línguas-culturas" (MENDES, 2015, p. 218). Essas diferenças citadas por Mendes (2015) não se manifestam apenas entre países, mas também no interior deles entre suas regiões, estados, cidades, municípios, que, como dizem Mollica; Braga (2004), por influência de fatores linguísticos e extralinguísticos, sofrem variação linguística, o que dá a essas comunidades características linguísticas próprias.

Ao assumir a perspectiva de língua-cultura, faz-se necessário esclarecer que consideramos que a cultura,

[...] engloba uma teia complexa de significados que são interpretados pelos elementos que fazem parte de uma mesma realidade social, os quais a modificam e são modificados por ela. Esse conjunto de significados inclui as tradições, os valores, as crenças, as atitudes e conceitos, assim como os objetos e toda a vida material [considera-se, também, que a cultura] não é inteiramente homogênea e pura, mas constrói-se e renova-se de maneira heterogênea através dos fluxos internos de mudança e do contato com outras culturas; [e] está presente em todos os produtos da vivência, da ação e da interação dos indivíduos; portanto, tudo o que é produzido, material e simbolicamente, no âmbito de um grupo social é produto da cultura desse grupo (MENDES, 2015, p. 218).

Desse modo, ao considerar língua e cultura como mutáveis e heterogêneas, fazse necessária uma abordagem de ensino de PLE que considere não apenas o ensino de estruturas formais da língua e de seu uso, mas também uma que seja capaz de abarcar toda a diversidade linguística e cultural de um povo, proporcionando ao aluno conhecer a língua-cultura do outro, (re)construir significações e se (re)conhecer a partir dela, por meio de um ensino intercultural (MENDES, 2012, 2015), que permite o deslocamento do "interesse do conhecimento de línguas stricto sensu para as relações que se desenvolvem na e com a língua a ser aprendida, e para os sujeitos que estão em interação" (MENDES, 2012, p. 359).

No entanto, como observa Hurstel (2004, p. 27 apud MENDES, 2012, p. 359), "a interculturalidade não existe, temos que inventá-la". Isso consiste em dizer que, mesmo reconhecendo a diversidade cultural existente nas sociedades, não significa que as diferenças serão aceitas ou que serão construídas ações mais integradoras, é necessário, além de reconhecer a multiculturalidade, construir um diálogo e uma integração entre as 
diferenças reais do mundo que nos cerca. Mendes (2012, p. 360) aponta para a necessidade de sermos agentes dessa interculturalidade que pode ser definida como

um [...] esforço, uma ação integradora, capaz de suscitar comportamentos e atitudes comprometidos com princípios orientados para o respeito ao outro, as diferenças, a diversidade cultural que caracteriza todo o processo de ensinoaprendizagem, seja ele de línguas ou de qualquer outro conteúdo escolar.

Sabemos que o multiculturalismo brasileiro é marcado por um pluralismo linguístico, que, muitas vezes, é ofuscado por culturas e variantes linguísticas, as quais, por questões diversas, acabam por adquirir maior prestígio social. Esse julgamento de valor emitido pelos falantes sobre as diversidades linguísticas influencia na escolha de suas variedades de fala e na eleição de uma variedade linguística padrão, em detrimento de outras que sofrem uma avaliação social negativa.

Nas instituições que ensinam o PLM, as variedades menos prestigiadas não são abordadas, e o foco do ensino está na variedade padrão encontrada na Gramática Normativa (BATISTA; ALARCON, 2012), ou seja, não é considerada a parte cultural que constitui a língua. A ausência de instrução/formação sobre o ensino de PLE faz com que, muitas vezes, os professores passem essa metodologia para o trabalho com o Português como Língua Estrangeira, que tem necessidades específicas. Afinal, os alunos de PLE não têm o Português como competência comunicativa, por isso precisam acessar a variedade linguístico-cultural, (re)conhecer-se e se (re)significar na língua alvo, considerando a interação entre a cultura lusófona e a sua.

Desse modo, ao basear o processo no ensino de PLM, não são atendidas as necessidades de um falante de outras línguas-culturas para aprender o Português, caindo-se no equívoco de ensinar

"o genérico de LM [Língua Materna] com pressupostos inadequados que indicam, por exemplo, uma análise voltada para a escritura, a leitura de antemão prioritárias, para o léxico e para as regras gramaticais em frases de pouca contextualização como é frequentemente praticado em sala de aula de LM" (BATISTA; ALARCON, 2012, p. 2).

No processo de ensino-aprendizagem, é essencial reconhecer a heterogeneidade da língua e a sua relação com a cultura. No entanto, deve-se saber que o trabalho com a cultura no ensino de PLE não deve ser separado da língua. Seria um equívoco, por 
exemplo, abordar o cultural, como temáticas e/ou conteúdos, separado do gramatical da língua (MENDES, 2015), pois aprender uma língua é aprender a estar, a interagir socialmente nela, e esse processo envolve muito mais que o domínio das estruturas linguísticas e de curiosidades acerca da cultura dos luso-falantes, no caso da Língua Portuguesa. Desse modo, conforme Mendes (2012, p. 362), "ensinar e aprender uma nova línguacultura deve ser, portanto, um processo em duas vias",

[...] da línguaculturaalvo em relação às línguasculturas que estão aliem interação e viceversa. Professores e aprendizes, desse modo, devem poder compartilhar na sala de aula, além do conhecimento relativo à língua que está sendo ensinada e aprendida, toda uma rede de conhecimentos e informações que fazem parte dos seus mundos culturais específicos, fazendo de cada sujeito em interação uma fonte complexa e diversificada de conhecimento potencial - sujeitos como mediadores culturais.

Mendes (2012, p. 264) alerta que "em uma abordagem intercultural, dessa forma, as experiências de ensinar e aprender uma nova línguacultura devem ser significativas, desenvolvidas dentro de contextos e voltadas para a interação entre os sujeitos participantes do processo de aprendizagem". E, ainda nas palavras da autora,

Fomentar o diálogo entre o aprendiz de LE/L2 e o Português é colocá-lo em contato e confronto com a língua-cultura brasileira e com a sua própria língua-cultura revisitada. Dialogar dentro da interculturalidade significa, portanto, abrir-se para a outra cultura e deixar-se ver pelo outro com o qual se estabelece o diálogo (MENDES, 2012, p. 361).

Ora, se a interculturalidade não é um "pacote" que se possa comprar pronto, mas que, antes, deve ser construída, é necessário um esforço para a construção de um material específico que incentive o estabelecimento de um diálogo intercultural. Sob essa ótica, é importante afirmar que, [...]os materiais [...] devem ser significativos, representar um conhecimento potencial que desejamos que o aluno internalize e use, e não dados prontos, definidos a priori e que devem seguir um modo específico de serem explorados (MENDES, 2012, p. 264).

Assim, o material utilizado não só deve se ajustar aos contextos específicos de experimentação, como também às necessidades dos sujeitos participantes da interação. Portanto, deve funcionar como "suporte, apoio, fonte de recursos para que se construam, 
em sala de aula, ambientes propícios à criação de experiências na/com a línguacultura alvo" (MENDES, 2012, p. 267). Daí emerge, portanto,

[...] a necessidade de os exemplares [os materiais didáticos] serem representativos das variadas situações sociais de uso da linguagem. Cada texto selecionado (em seu sentido amplo) será uma amostra da línguacultura em foco, em toda a sua potencialidade linguística e cultural (MENDES, 2012, p. 271).

Foi levando tudo isso em consideração que buscamos adequar os conteúdos discutidos nos cursos de Português como Língua Estrangeira do ISF/UFAL, de modo a adotar uma abordagem que permitisse aos alunos, em interação uns com os outros e com os professores, experimentar modos de ser, de viver e de estar socialmente em Português, e em Português Brasileiro, uma vez que o Português é cheio de matizes por ser falado em países e contextos diversos (MENDES, 2015), assim como buscamos compreender o que é estar socialmente nas línguas dos países de origem dos estudantes.

Apresentamos, a seguir, um relato das aulas que tiveram como base os conceitos aqui apresentados.

\section{Um olhar sobre os cursos de Português no ISF-UFAL}

As discussões apresentadas nesta seção têm como base observações de aulas ministradas em cursos ofertados pelo programa Idiomas sem Fronteiras (ISF), no Núcleo de Português para Estrangeiros, a alunos estrangeiros que estudam nos cursos de Graduação e Pós-Graduação na Universidade Federal de Alagoas, Campus A.C. Simões.

Embasados na Linguística Aplicada e em sua busca pela descrição da realidade, realizamos uma pesquisa de cunho qualitativo, que descreve e reflete sobre a prática docente e a receptividade discente quanto a essas práticas, a partir de um estudo de caso avaliativo (PAIVA, 2019).

Os cursos ofertados, "Leitura e produção de textos" e "Aspectos culturais do Nordeste brasileiro pelo olhar do Cinema", foram pensados de modo a estabelecer uma interação verbal com os/as alunos/as e, desse modo, abordar um ensino baseado na interculturalidade. Importa ressaltar que, para definir quais cursos poderiam interessar ao nosso público, elaboramos um questionário e enviamos para todos os estrangeiros com vínculo com a Universidade Federal de Alagoas.

A princípio, considerando o contexto no qual os/as discentes estavam inseridos, propusemos três ofertas, uma abordando a língua-cultura através do olhar do Cinema 
brasileira, e outras duas voltadas à leitura e à produção textual, uma delas com ênfase em diversos gêneros textuais do cotidiano e outra apenas nos gêneros acadêmicos. Os interessados optaram pelos cursos de cultura, por meio do Cinema, e leitura e produção com ênfase em gêneros acadêmicos, visto participarem de programas de Pós-Graduação, os quais exigem o domínio desses gêneros.

Nossa preocupação em compor um curso que atendesse as necessidades dos/as alunos/as partiu do pressuposto de que "[...] qualquer que seja o conteúdo que se deseje ensinar ou aprender [...], [este] deve ter significado para aquele que aprende, deve poder ser incorporado pela rede de significados que dá sentido à sua vida" (MENDES, 2012, p. 264). O conteúdo do qual tratamos nos cursos exposto através desta ótica e metodologia não foi, apenas, dotado de significado para a vida acadêmica dos estudantes, mas também para a sua vida enquanto sujeitos falantes, pois buscamos articular o conteúdo programático do curso com temáticas que proporcionassem uma interação entre as culturas dos sujeitos envolvidos no processo de ensino-aprendizagem do PLE.

Essa experiência é relatada e analisada com base em nossa experiência em cada curso, sendo dividida em duas partes, as quais apresentamos a seguir.

\section{Curso de Leitura e Produção de Textos}

O curso "Leitura e produção de textos" abordou questões linguísticas, discursivas e culturais do Português Brasileiro, por meio do trabalho com gêneros acadêmicos. 0 curso foi conduzido de modo que os discentes conseguissem interpretar, compreender e produzir, em uma relação dialógica e intercultural, o gênero Artigo acadêmico e outros gêneros que se relacionam de algum modo com ele, como a Resenha, a Revisão de Literatura e o Resumo.

Uma de nossas dificuldades iniciais ao trabalhar com gêneros acadêmicos foi estabelecer uma relação intercultural nesse processo de ensino-aprendizagem, visto que esses textos têm como especificidade uma linguagem bastante formal e científica. No entanto, apesar das adversidades, conseguimos, em conjunto, promover uma alteridade cultural a partir de discussões de temas integrantes da vida dos discentes, como sujeitos em seus países de origem ou como expatriados no Brasil.

Em um desses momentos, por exemplo, foi-lhes apresentado um vídeo que trata da diversidade e do preconceito linguístico, cuja duração é de pouco mais de três minutos. Após a sua reprodução, pedimos que os/as estudantes relatassem o que tinham 
entendido do vídeo, qual o posicionamento do autor diante do tema e quais as justificativas que ele usava para sustentar sua posição diante da temática abordada. Em seguida, perguntamos aos discentes se havia variação linguística em seus países, se percebiam a existência de algumas falas ou formas linguísticas mais prestigiadas que outras e se eles haviam alguma vez sofrido preconceito por causa da sua língua ou seu modo de falar no Brasil ou em seu país de origem.

Este foi o passo inicial de um duplo movimento para as aulas. Por um lado, discutiram-se questões linguísticas propriamente ditas, isto é, a variedade linguística como natural - tão grande no Brasil, como no Nordeste- e o preconceito linguístico. Em nossas discussões, os/as alunos/as alegaram ter sofrido preconceito linguístico em seus países. Dois alunos colombianos relataram que o falar de sua região é, em geral, mal visto por conta de seu tom mais alto que os falares de outros locais. Eles relataram, também, que, no meio acadêmico pelo qual tinham mais contato com brasileiros, não sofreram preconceito relacionado à sua língua, mas perceberam que os próprios falantes alagoanos discriminavam a sua variedade linguística, ao rirem um dos outros por usarem

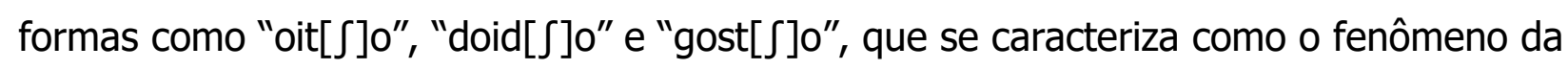
palatalização progressiva, muito comum em Maceió e é, ao que parece, estigmatizado (OLIVEIRA, 2017).

Todo o diálogo estabelecido, ao início da aula, foi igualmente útil para a abordagem de questões mais específicas, voltadas aos propósitos específicos do curso. Afinal, as respostas e descrições que obtivemos às questões iniciais - "Qual o posicionamento do autor no vídeo?", etc. - , foram, elas próprias, "resumos" feitos pelos alunos, pois se caracterizavam pela ênfase e descrição dos aspectos mais importantes do vídeo, mesmo que, em certos momentos, perpassados pelo relato de vivências pessoais. Tais reflexões permitiram trabalhar os aspectos mais teóricos e metodológicos do conteúdo propriamente dito, sem a exclusão de uma abordagem intercultural dentro de um curso que, a princípio, parecia dar pouca abertura a essa perspectiva.

Abordar o gênero resumo, relacionando-o com o preconceito linguístico, além de permitir que fossem trabalhados aspectos relacionados à estrutura do gênero, proporcionou uma discussão sobre variações e significações sociais de uma língua-cultura que reflete um todo múltiplo e plural, constituído pela identidade, diversidade, desigualdades de gêneros, de religiões, de classes de uma sociedade que está organizada em padrões culturais diversos (BATISTA; ALARCÓN, 2012). 
O intercultural esteve presente novamente na aula em que abordamos o gênero Resenha. Introduzimo-la com a reprodução de um vídeo intitulado "O que os americanos pensam do Brasil?", no qual facilmente identificamos a reprodução de estereótipos associados ao Brasil e aos brasileiros. A partir disso, discutimos com os estudantes esta representação estereotipada, ou seja, aquela preexistente e resultante de avaliações negativas de sujeitos por suas línguas e suas culturas (AMOSSY, 2008), ao questioná-los sobre o que pensavam sobre nosso país antes da vinda para cá, que eles também tinham visões deturpadas de nossos costumes. Ainda neste mote, questionamos sobre possíveis rotulações relacionadas a sua origem e sua cultura

A ligação com o gênero resenha se deu inicialmente pela explicitação de que a discussão empreendida até ali, a descortinação de visões estigmatizantes sobre o Brasil e o brasileiro, apesar de parecer distante do gênero acadêmico abordado, tinha relação, uma vez que ambas têm como partida a avaliação, quer seja sobre o outro, sujeito de uma identidade e uma cultura, quer seja de um texto produzido por um indivíduo também associado a identidades e culturas que Ihes perpassam.

Discutimos, igualmente, o fato de aqueles estereótipos terem um ponto de apoio e de referência facilmente identificáveis no vídeo pela fala dos participantes: a mídia. Era clara a veiculação dessas visões a filmes e a notícias sobre o Brasil e os brasileiros. Ora, ao resenharmos um livro ou obra artística, partimos de um contexto específico, um espaço de referência - aquele a que a obra pertence, de qual assunto trata, com quais obras se relaciona, qual as áreas em que se insere - que direciona a crítica, a avaliação e o juízos emitidos de modo a apreendê-la e avaliá-la.

Apesar das diferentes relações, conseguimos, de algum modo, articular essas discussões críticas-reflexivas com os aspectos estruturais do gênero acadêmico propriamente dito e com sua linguagem mais formal. Em outras palavras, conseguimos relacionar questões específicas do gênero com temáticas que levaram a (re)construção de um conhecimento baseado na interculturalidade.

Podemos concluir, por esse breve relato de uma aula do curso, que obtivemos êxito quanto à abordagem, pois foram exploradas as potencialidades linguísticas de expressão e argumentação dos estudantes, aliando a discussões pertinentes na/à línguacultura alvo (o Português, e, mais especificamente, o Português Brasileiro) e sua pluralidade, oportunizando e favorecendo um olhar sobre o outro, sobre a língua-cultura 
dos estudantes com os quais interagimos e junto aos quais buscamos construir o conhecimento.

\section{Aspectos culturais do nordeste brasileiro pelo olhar do cinema}

O curso "Aspectos culturais do Nordeste brasileiro pelo olhar do cinema" teve como objetivo abordar questões acerca da Língua Portuguesa e das diversidades culturais do Nordeste através da produção cinematográfica nacional e seus gêneros fílmicos, como comédia, ação, romance, entre outros, proporcionando ambientes adequados para discussões orais e escritas em Língua Portuguesa. Os filmes permitem uma pluralidade de espaços que proporcionam diálogos acerca de temas como a língua, o social, o humano, o político, o geográfico, o econômico entre outros.

Entre os filmes abordados, trabalhos o drama brasileiro Entre Irmãs, de 2017, brasileiro baseado no livro A Costureira e o Cangaceiro (2009), de Frances de Pontes Peebles. Além do longa-metragem, ao qual os alunos assistiram em momentos assíncronos, optamos por usar outros materiais de apoio que enriquecessem ainda mais as aulas, como entrevistas, artigos sobre a mulher no Nordeste e sobre o movimento social do Cangaço, além de vídeos com temas abordados, como o vocabulário nordestino e informações sobre Lampião e seus seguidores.

No primeiro encontro, pequenos trechos do filme Entre Irmãs (2017) foram apresentados para os alunos, além de alguns vídeos e definições sobre cultura baseadas no livro Língua, Cultura e Ensino (2006), que também nos embasou nas discussões acerca do que é cultura, cultura brasileira (especialmente a nordestina), e a cultura de origens dos alunos.

Apesar da dificuldade de entender a língua, cada um com seu nível de proficiência, os discentes conseguiram entender o filme e destacaram o que mais Ihes interessou. Uma das alunas, mestranda em Arquitetura, relatou que os prédios e as estruturas vistas durante o filme chamaram muita sua atenção, o que a fez focar neste aspecto do longametragem, comparando com sua realidade de estudos e sua cultura.

Além disso, alguns temas abordados pelo filme, como a condição da mulher, o cangaço, a homossexualidade, o machismo, a xenofobia, a imigração, a diferença entre as cidades do interior e as capitais, a pobreza etc., foram problematizados e discutidos, sempre tendo como fundo o diálogo intercultural. 
As discussões foram muito produtivas, pois os alunos se expressaram em Língua Portuguesa sobre os temas a partir das visões de mundo deles e suas vivências de imigrantes. Pudemos, assim, por meio dessas discussões em Português, conhecer e compreender seus aspectos culturais, dando espaço para os discentes expressarem suas ideias acerca dos temas abordados, o que configura um momento de total interculturalidade, pois foi possível, para alunos e professores, conhecer a cultura do outro e se (re)significar a partir dela.

O diálogo entre as diversas línguas-culturas dos alunos sempre esteve presente nas aulas dos cursos do NucLi- Português para Estrangeiros, um ponto bastante positivo, de acordo com os discentes, os quais relataram ter apreciado a oportunidade de expressarem suas opiniões em Português em um espaço em que puderam ser ouvidos.

Acreditamos que, por serem estrangeiros, os alunos podem ter inúmeras dificuldades de expor suas concepções no seu cotidiano dentro e fora da Universidade. Assim, esses momentos em que os ouvimos interagindo sobre aspectos de suas culturas de origem e os aspectos culturais brasileiros, e as situações diversas em há vivência por meio de outra língua-cultura, foram fundamentais nas aulas do ISF, uma vez que a cultura pode contribuir tanto para o processo de aprendizagem do aluno de PLE, como para a formação acadêmica dos professores.

Muitas vezes, temos uma ideia de que, ao trabalhar com aspectos culturais no ensino de uma segunda língua, como Português para Estrangeiros, deixamos os aspectos linguísticos de fora. Nas aulas do ISF, a análise linguística esteve presente em todos os momentos de discussão em português, como quando foi abordado o vocabulário regional do Nordeste, em que a variação linguística, como no curso de Produção Textual, teve destaque. Termos como visse, traste, matuta, cangaceiro, sonso, carcará, rapariga, coitadinha, babaca, e expressões como "não seja grossa" e "tu é lerda", entre outras, foram explanados em vistas de ampliar a competência de interação na variedade nordestina do Português pelos alunos.

Metodologicamente, para auxiliar na compreensão dos termos e expressões, apresentamos um vídeo intitulado "Palavras Nordestinas", disponível no YouTube, que fala informalmente sobre algumas palavras e expressões utilizadas aqui no Nordeste. 0 vídeo foi passado duas vezes, voltando-se, após a exibição, à lista de palavras e expressões, explicando-as individualmente. Durante o esclarecimento dessa língua- 
cultura nordestina, buscamos, além de explicar a palavra, explicar suas significações sociais nos diversos contextos reais de uso da língua na comunidade alagoana.

Nas aulas em que trabalhamos com o filme Auto da Compadecida (2001), adaptação da peça teatral escrita por Ariano Suassuna em 1955, também discutimos a língua-cultura, com ênfase no português praticado em Alagoas, comunidade de fala habitada pelos discentes, destacando fenômenos variáveis, sobretudo fonéticofonológicos. Um exemplo disso está na palavra "mesmo", que pode ser praticada também como /mermu/ e /memo/, pois uma das discentes pensou serem palavras distintas e não variantes do mesmo termo. Em nossa aula, empreendemos discussões, a partir dessa observação da aluna, no sentido de mostrar que essas formas linguísticas são variantes fonéticas de uma mesma palavra, tendo ambas o mesmo significado, mas valores sociais distintos.

Outros fenômenos abordados foram o apagamento do /d/ no grupo dos gerúndios como em /andano/ e /pegano/; a realização de epênteses como em /fulor/, a redução de terceira pessoa do plural como em /cantaru/, /falaru/ e /comeru/ que também são fenômenos realizados no português alagoano a depender do contexto de fala, das relações interpessoais dos falantes, da sua idade, escolaridade, gênero, entre outros fatores sociolinguísticos, o que mostra que essas palavras têm significações, valores sociais e culturais diversos e que, ao abordar essa variação, estamos ensinando uma língua que se (re)significa em sua relação com a língua-cultura do outro, mostrando que o ensino do PLE não deve restringir o ensino de cultura a um conjunto de temas ao lado do gramatical, pois ao separar língua e cultura caímos no erro de ensinar uma língua estática que não condiz com a realidade linguística dos falantes nativos da língua alvo.

Na última aula do curso, discutimos o filme Lisbela e o Prisioneiro (2003). Tratamos da própria linguagem do cinema e como ela é abordada pela produção, que realiza toda uma discussão metalinguística sobre o Cinema, através de um jogo que explora o "filme dentro do filme" - temática bastante recorrente, visto que a personagem principal, Lisbela, é uma amante do cinema estadunidense, e, em diversas cenas, aparece justamente assistindo, encantada, a filmes americanos. Também discutimos algumas expressões/palavras típicas do Nordeste, que aparecem na produção - uma prática desenvolvida por nós desde as primeiras aulas dos cursos de Português no ISF-UFAL.

A análise lexical atrelou-se a reflexões sobre as temáticas transversais constantes do filme. Algumas expressões, como "baitola", termo pejorativo para referir-se a 
homossexuais, relaciona-se com a masculinidade e as características ligadas às ideias associadas ao masculino ali presentes e bastante fortes no Nordeste, especialmente nos anos 1950/1960, período aproximado em que o filme é ambientado. Outro exemplo dessa articulação foi a apresentação do termo "corpo fechado", que remete à religiosidade, tratando-se de "proteção mística" a uma pessoa, trazendo à luz a forte presença, no Nordeste, da religiosidade como característica da região, o que levou os alunos a associarem às suas regiões.

Essa tensão esteve em consonância com a abordagem que optamos por adotar em nossos planejamentos, isto é, a concepção de língua-cultura e o ensino intercultural. Afinal, não só discutimos essas expressões em seus contextos culturais significativos, como também utilizamos esse gancho para olharmos para a cultura do outro com o olhar altruísta que se espera nessa abordagem. Como exemplo, um momento bastante rico foi a descrição da religiosidade em Guiné-Bissau, país de origem de um dos alunos, que descreveu a forte presença do Cristianismo se sobressaindo às diversas religiões cultuadas pelos povos originais antes da colonização europeia.

Expusemos aqui momentos de diálogo intercultural que buscamos estabelecer com os discentes, pois discutimos não só os aspectos gramaticais da Língua Portuguesa, como estabelecemos relações entre a língua-cultura brasileira com outra(s) língua(s)cultura(s), seguindo o que Mendes (2015, p. 218) assevera quando afirma que a cultura "está presente em todos os produtos da vivência, da ação e da interação dos indivíduos; portanto, tudo o que é produzido, material e simbolicamente, no âmbito de um grupo social é produto da cultura desse grupo".

A língua, como instância de uso e de interação, "resultado de práticas de significação situadas e marcadas historicamente" (MENDES, 2015, p. 219) não está, portanto, dissociada da cultura e, na medida em que o diálogo intercultural ocorre, quando nos abrimos à cultura do outro e por ela passamos a nos enxergar como seres culturais, como aconteceu no curso, o ensino se faz mais produtivo, resultando em aprendizagens de fato.

\section{Considerações finais}

Não obstante a referida ausência de uma formação específica para o ensino de PLE no âmbito do curso de Letras da UFAL, os cursos do ISF foram ofertados com êxito. Naturalmente, deparamo-nos em nossas aulas com as dificuldades que a abordagem 
intercultural impõe, mas soubemos contorná-las. Através de um esforço conjunto, criamos a interculturalidade em classe, tarefa necessária para a condução de um ensino intercultural, conforme Mendes (2015), buscando sempre pôr em diálogo a língua-cultura brasileira com a dos estudantes, mesmo num curso cuja abordagem parecia nos dar pouca abertura, como o de "Leitura e produção de textos". Longe de ensinarmos apenas o formal, buscamos ensinar a língua em sua totalidade, que envolve o político, o ideológico, o cultural, como preconizam Batista e Alarcón (2012).

Conforme os relatos, articulamos discussões sobre o uso linguístico, a variação, as avaliações sociais atribuídas a certas variantes no Brasil a discussões que nos permitem (re)conhecer esses componentes do social e do linguístico, que se influenciam mutuamente, nas culturas dos estudantes. Chamamos a atenção para os materiais utilizados nas aulas, os quais devem ser "representativos das variadas situações sociais de uso da linguagem", conforme vimos em Mendes (2015). Ora, não apenas buscamos discutir essa representatividade a partir das discussões proporcionadas pelas obras fílmicas, em que diversas situações sociais do uso linguístico nordestino se manifestam mais explicitamente, mas também fomentar essa discussão nas aulas de gêneros acadêmicos através dos materiais escolhidos.

Com isto, pensamos ter contribuído para a situação (no seu sentido de situar-se) dos estudantes no Português não só lhes fornecendo aparatos estritamente formais do linguístico, extremamente úteis para eles, alunos dos cursos da UFAL, mas igualmente culturais, muito úteis para eles agora enquanto sujeitos. Buscamos, assim, contribuir para que os estudantes experienciassem estar em Língua Portuguesa a partir de um diálogo e de um olhar para a sua própria língua-cultura de origem e, da mesma forma, nós, professores, enquanto sujeitos participantes deste processo, reconhecemo-nos neste espaço como mediadores culturais, e reconhecemos o outro como partícipe dessa mediação. Portanto, empreendemos o movimento de mão-dupla, nos termos de Mendes (2015) que envolve o ensino-aprendizagem de uma língua-cultura como o Português para Estrangeiros.

\section{Referências}

ALMEIDA FILHO, Jose Carlos Paes. Ensino de português língua estrangeira/EPLE: a emergência de uma especialidade no Brasil. In: LOBO, T. et al. (org.). Rosae: linguística histórica, história das línguas e outras histórias. Salvador: EDUFBA, 2012. p. 723-728. 
Disponível em: https://books.scielo.org/id/67y3k/pdf/lobo-9788523212308-51.pdf. Acesso em: 05 jan. 2021.

AMOSSY, Ruth (org.). Imagens de si no discurso: a construção do ethos. São Paulo: Contexto, 2008.

BATISTA, Marília Carvalho; ALARCóN, Yéris Gerardo Láscar. Especificidades do ensino de PLE. Revista SIPLE, Brasília, n. 4, maio, 2012.

MENDES, Edleise. Aprender a ser e a viver com o outro: materiais didáticos interculturais para o ensino de português LE/L2. In: SCHEYERL, Denise Chaves de Menezes; SIQUEIRA, Sávio (org.). Materiais didáticos para o ensino de línguas na contemporaneidade: contestações e proposições. Salvador: EDUFBA, 2012. p. 355-378.

MENDES, Edleise. A ideia de cultura e sua atualidade para o ensino-aprendizagem de LE/L2. In: EntreLínguas, Araraquara, v. 1, n. 2, p. 203-221, jul./dez. 2015.

MOLLICA, Maria Cecilia; BRAGA, Maria Luiza. Introdução à sociolinguística: o tratamento da variação. São Paulo: Contexto, 2004.

OLIVEIRA, Almir Almeida. Processos de palatalização das oclusivas alveolares em Maceió. 2017. Tese (Doutorado em Letras e Linguística). Faculdade de Letras, Universidade Federal de Alagoas, Maceió, 2017. Disponível em:

http://www.repositorio.ufal.br/jspui/bitstream/riufal/1784/1/Processos\%20de\%20palata liza\%c3\%a7\%c3\%a30\%20das\%20oclusivas\%20alveolares\%20em\%20Macei\%c3\%b3. pdf. Acesso em: 10 nov. 2019.

PAIVA, Vera Lúcia Menezes de Oliveira. Manual de pesquisa em estudos linguísticos. São Paulo: Parábola, 2019.

Submetido em: 28 set. 2021. Aceito em: 28 out. 2021. 